\title{
Communication
}

\section{Seasonality of Acute Lyme Disease in Children}

\author{
Kathryn M. Sundheim 1,*, Michael N. Levas ${ }^{2}$, Fran Balamuth ${ }^{3}$, Amy D. Thompson ${ }^{4}$, Desiree N. Neville ${ }^{5}$, \\ Aris C. Garro ${ }^{6}$, Anupam B. Kharbanda ${ }^{7}$, Michael C. Monuteaux ${ }^{8}$ and Lise E. Nigrovic ${ }^{8, *(D)}$ \\ on behalf of the Pedi Lyme Net ${ }^{+}$
}

check for updates

Citation: Sundheim, K.M.; Levas, M.N.; Balamuth, F.; Thompson, A.D.; Neville, D.N.; Garro, A.C.;

Kharbanda, A.B.; Monuteaux, M.C.; Nigrovic, L.E., on behalf of the Pedi Lyme Net. Seasonality of Acute Lyme Disease in Children. Trop. Med. Infect. Dis. 2021, 6, 196. https:// doi.org/10.3390/tropicalmed6040196

Academic Editors: Felipe J. ColónGonzález and Yang Liu

Received: 28 September 2021 Accepted: 4 November 2021 Published: 9 November 2021

Publisher's Note: MDPI stays neutral with regard to jurisdictional claims in published maps and institutional affiliations.

Copyright: (c) 2021 by the authors. Licensee MDPI, Basel, Switzerland. This article is an open access article distributed under the terms and conditions of the Creative Commons Attribution (CC BY) license (https:/ / creativecommons.org/licenses/by/ $4.0 /)$.
1 Department of Pediatrics, Boston Children's Hospital, Boston, MA 02115, USA

2 Division of Pediatric Emergency Medicine, Medical College of Wisconsin, Wauwatosa, WI 53226, USA; mnlevas@mcw.edu

3 Division of Emergency Medicine, Children's Hospital of Philadelphia, Philadelphia, PA 19104, USA; balamuthf@chop.edu

4 Departments of Pediatrics and Emergency Medicine, Nemours / Alfred I. duPont Hospital for Children, Wilmington, DE 19899, USA; amy.thompson@nemours.org

5 Division of Emergency Medicine, UPMC Children's Hospital of Pittsburgh, Pittsburgh, PA 15224, USA; desiree.neville@chp.edu

6 Departments of Pediatrics and Emergency Medicine, Rhode Island Hospital and Brown University, Providence, RI 02903, USA; arisgarro1@gmail.com

7 Division of Emergency Medicine, Children's Minnesota, Minneapolis, MN 55404, USA; anupam.kharbanda@childrensmn.org

8 Division of Emergency Medicine, Boston Children's Hospital, Boston, MA 02115, USA; michael.monuteaux@childrens.harvard.edu

* Correspondence: kathryn.sundheim@childrens.harvard.edu (K.M.S.); lise.nigrovic@childrens.harvard.edu (L.E.N.)

+ Collaborators of Pedi Lyme Net are indicated in the Acknowledgment section.

\begin{abstract}
Due to the life cycle of its vector, Lyme disease has known seasonal variation. However, investigations focused on children have been limited. Our objective was to evaluate the seasonality of pediatric Lyme disease in three endemic regions in the United States. We enrolled children presenting to one of eight Pedi Lyme Net participating emergency departments. Cases were classified based on presenting symptoms: early (single erythema migrans (EM) lesion), early-disseminated (multiple EM lesions, headache, cranial neuropathy, or carditis), or late (arthritis). We defined a case of Lyme disease by the presence of an EM lesion or a positive two-tier Lyme disease serology. To measure seasonal variability, we estimated Fourier regression models to capture cyclical patterns in Lyme disease incidence. While most children with early or early-disseminated Lyme disease presented during the summer months, children with Lyme arthritis presented throughout the year. Clinicians should consider Lyme disease when evaluating children with acute arthritis throughout the year.
\end{abstract}

Keywords: Lyme disease; seasonality; pediatric; arthritis

\section{Introduction}

Lyme disease is the most commonly reported vector-borne illness in the United States [1], and children are disproportionately affected [2]. In the life cycle of the Ixodes scapularis tick, which harbors the Borrelia spirochete, nymphal ticks are responsible for the majority of disease transmission and bite in the spring and the early summer. Though capable of biting throughout the year, adult ticks are much larger and thus often removed prior to disease transmission [3]. Recognizing this seasonal transmission cycle, clinicians are quick to suspect Lyme disease in the summer and early fall but may not consider Lyme disease during the winter months. However, while the symptoms of early-localized Lyme disease (single erythema migrans (EM) lesion) and early-disseminated disease (multiple EM lesions, headache, cranial neuropathy, or carditis) can present within days to weeks of a tick bite, late disease (arthritis) often manifests months later [3]. As a result, Lyme 
arthritis may present throughout the year, even when clinicians are less likely to consider Lyme disease. To this end, we explored the seasonality of Lyme disease overall and by clinical presentation in a multi-center cohort of children with acute Lyme disease.

\section{Materials and Methods}

We enrolled children undergoing clinical evaluation for Lyme disease presenting between 1 June 2015 and 20 July 2021 to one of the eight Pedi Lyme Net participating emergency departments, with exact enrollment dates varying by participating centers [4] The Institutional Review Board (IRB) at each center approved the study protocol with permission for data sharing.

We defined a case of Lyme disease with either a physician-diagnosed EM lesion or a positive two-tier serology in a child with symptoms compatible with acute Lyme disease [5]. For cases of Lyme disease, patients were labeled based on the stage of presenting symptoms: early (single EM lesion), early-disseminated (multiple EM lesions, headache, cranial neuropathy, or carditis), or late (arthritis). For the purposes of this analysis, we grouped children with early and early-disseminated Lyme disease. All other children were classified as clinical mimics of Lyme disease.

We first compared children with Lyme disease to clinical mimics using the Chi square test for categorical variables and the t-test for continuous variables. Next, we compared the clinical presentations by season for children with Lyme disease versus the clinical mimics. Finally, we examined the proportion of early or early-disseminated as well as late Lyme disease cases by month of presentation.

To measure seasonal variability in Lyme disease presentation, we estimated logistic regression models with disease status as the dependent variable and sine and cosine terms as independent variables to capture cyclical patterns in incidence (i.e., Fourier regression) [6,7]. Models were estimated separately for early or early-disseminated and late Lyme disease and were adjusted for patient age, sex, and geographic region (New England, Mid Atlantic, or Upper Midwest) with clustering by participating center. We tested the null hypothesis that the seasonal pattern for initial presentation was the same for children with early or early-disseminated versus late Lyme disease.

Analyses were performed using STATA 16.1 (StataCorp, College Station, TX, USA).

\section{Results}

Of the 3180 enrolled children, $690(21.7 \%)$ had Lyme disease and $2490(78.3 \%)$ were clinical mimics. Of those with Lyme disease, 77 (11.2\%) had a single EM lesion, 247 (35.7\%) had early-disseminated disease, and $366(53.1 \%)$ had arthritis. Children with Lyme disease were less likely to be female but had a similar age distribution to those with alternate diagnoses (Table 1). The initial clinical presentations of children with Lyme disease differed from those of the clinical mimics.

Table 2 compares the clinical presentation by season for children with Lyme disease versus clinical mimics. Clinical mimics did not present more commonly during the peak Lyme disease season $(1418 / 1873(75.7 \%)$ peak season vs. 1072/1307 $(82.0 \%)$ non-peak season; $p=0.06$ ).

Children with early and early-disseminated Lyme disease most frequently presented in the summer months (June through August), while children with Lyme arthritis presented throughout the year (Figure 1). The seasonality of early or early-disseminated disease significantly differed from that of late disease $(p<0.001)$. 
Table 1. Comparison of clinical characteristics for children with Lyme disease versus clinical mimics.

\begin{tabular}{cccc}
\hline & $\begin{array}{c}\text { Lyme Disease } \\
\boldsymbol{n} \mathbf{6 8 9} \\
\boldsymbol{n} \mathbf{( \% )}\end{array}$ & $\begin{array}{c}\text { Clinical Mimics } \\
\boldsymbol{n} \mathbf{2 4 9 1} \\
\boldsymbol{n} \mathbf{( \% )}\end{array}$ & $\boldsymbol{p}$-Value \\
\hline Age (years) & $9(4)$ & $9(5)$ & 0.41 \\
\hline Female gender & $239(34.7)$ & $1158(46.5)$ & $<0.001$ \\
\hline Region & & & \\
New England & $249(36.1)$ & $939(37.7)$ & \\
MidAtlantic & $393(56.9)$ & $1422(57.1)$ & \\
Upper Midwest & $48(7.0)$ & $130(5.2)$ & \\
Clinical presentation & & & \\
EM lesion & $77(11.2)$ & $1183(47.5)$ & \\
Early-disseminated & $246(35.7)$ & $1198(48.1)$ & \\
Late & $366(53.1)$ & $110(4.4)$ & \\
Non-specific & $\mathrm{n} / \mathrm{a}$ & & \\
\hline * Mean (standard deviation). & & &
\end{tabular}

Table 2. Comparison of children with Lyme disease and clinical mimics who presented in the peak Lyme season versus the non-peak Lyme season.

\begin{tabular}{|c|c|c|c|}
\hline & $\begin{array}{c}\text { Peak } \\
\text { Lyme Season }^{\mathrm{a}} \\
n=1873 \\
n(\%)\end{array}$ & $\begin{array}{c}\text { Non-Peak } \\
\text { Lyme Season }^{b} \\
n=1307 \\
n(\%)\end{array}$ & $p$-Value \\
\hline \multicolumn{4}{|c|}{ Lyme disease $(n=690)$} \\
\hline Age (years) ${ }^{c}$ & $9(4)$ & $9(4)$ & 0.80 \\
\hline Female gender & $170(34.8)$ & $81(34.5)$ & 0.94 \\
\hline \multicolumn{4}{|l|}{ Clinical presentation } \\
\hline EM lesion & $69(14.1)$ & $8(3.4)$ & $<0.001$ \\
\hline Early-disseminated & $203(41.5)$ & $44(18.7)$ & \\
\hline Late & $183(37.4)$ & $183(77.9)$ & \\
\hline \multicolumn{4}{|c|}{ Clinical mimics $(n=2490)$} \\
\hline Age (years) ${ }^{c}$ & $9(5)$ & $9(5)$ & 0.34 \\
\hline \multicolumn{4}{|l|}{ Clinical presentation } \\
\hline Early-disseminated & $740(52.2)$ & $442(41.2)$ & $<0.001$ \\
\hline Late & $607(42.8)$ & $591(55.2)$ & \\
\hline Non-specific & $71(5.0)$ & $39(3.6)$ & \\
\hline
\end{tabular}
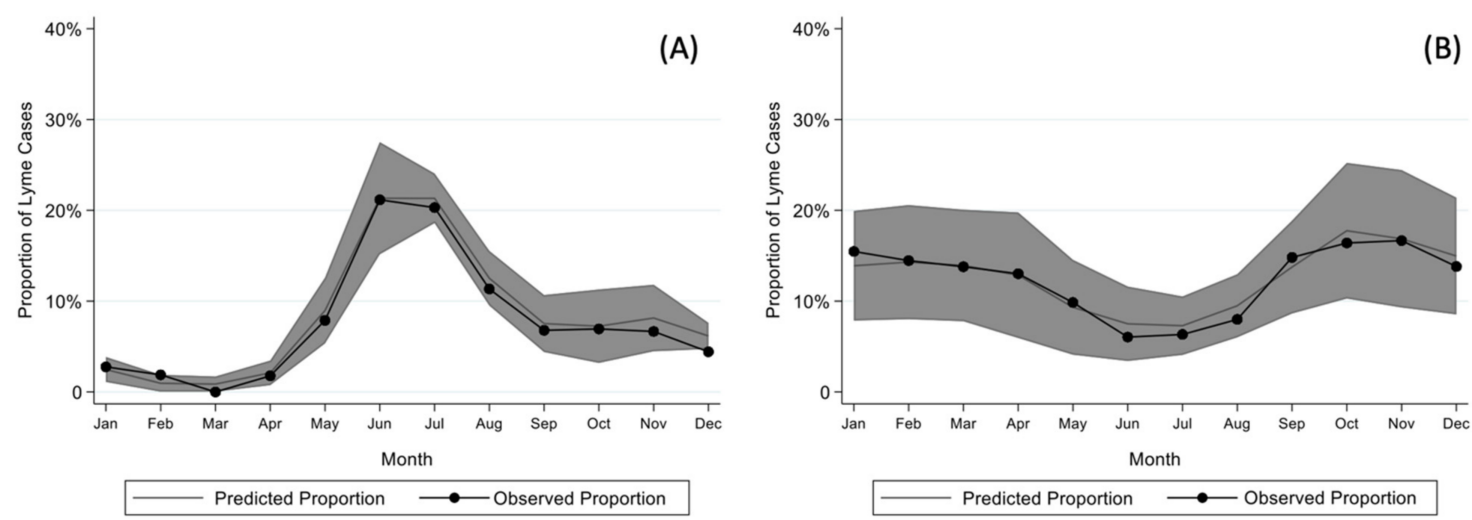

Figure 1. Model for seasonality of (A) early or early-disseminated and (B) late Lyme disease after adjusting for sex, age, year, and region as well as clustering by center with $95 \%$ confidence intervals. 


\section{Discussion}

In our multi-center prospective study of children undergoing evaluation for acute Lyme disease, early and early-disseminated Lyme disease peaked in the summer months. However, children with Lyme arthritis presented throughout the year. For clinicians evaluating a child for potential acute Lyme disease, Lyme arthritis has to be considered throughout the whole year, while early manifestations are more likely to occur during the peak Lyme season (May to October).

Prior work has highlighted the seasonal variation in Lyme disease presentation [2,8-10]; however, previously published population-based studies have been retrospective and not focused on children [2]. Pediatric studies have been small [9] or included only one disease stage $[8,10-12]$. We performed the first prospective evaluation of the seasonality of Lyme disease in children, accounting for patient level and center effects. Our next steps will be to develop tools for real-time estimate of the risk of Lyme disease based on a patient's clinical presentation, geographic location, and date of presentation.

The most frequent Lyme disease presentation in our pediatric cohort was arthritis. In North America, Lyme disease is nearly exclusively caused by Borrelia burgdorferi sensu stricto, while in Europe it is predominantly caused by Borrelia afzelii and Borrelia garinii, which leads to differences in clinical manifestations [13]. Importantly, musculoskeletal manifestations of Lyme disease have been more commonly reported in North America than in Europe [14,15].

B. burgdorferi, the causative agent of Lyme disease, is the most recognized and reported cause of tick-borne illness; however, multiple other bacterial and parasitic organisms are also carried by the Ioxodes scapularis tick and are increasingly recognized as causes of human illness [16-19]. Patients with any of these tick-borne infections alone or in combination with B. burgdorferi can present with symptoms similar to Lyme disease $[16,18,20,21]$. Multiplex polymerase chain reaction panels for tick-borne coinfections have demonstrated that a substantial portion of adults with Lyme disease have coinfections [22]. However, as children are not routinely tested, the frequency of these other tick-borne infections or coinfections in children undergoing evaluation for Lyme disease is not known. Future studies are needed to understand the optimal approach to tick-borne coinfections in children.

Our study had several limitations. First, because participating centers were all located in endemic Lyme disease areas, our findings cannot be applied to non-endemic regions. Second, we enrolled patients at selected study centers when study staff were available, limiting generalizability. Third, if providers were less likely to consider Lyme disease in certain months, the seasonality we demonstrated may be partially due to providers' decision to test rather than the true incidence of disease. Fourth, as we did not collect the duration of arthritis symptoms prior to evaluation, we cannot compare the duration of illness for children with Lyme arthritis by season. However, the vast majority of children presented to the emergency department with acute onset symptoms. Last, we may have misclassified cases of Lyme disease, as EM lesions were diagnosed by treating providers and may have included lookalike rashes (e.g., cellulitis or ring worm) and Lyme disease serology can be falsely negative early in disease or falsely positive after previous infection $[23,24]$.

In conclusion, children with Lyme arthritis present throughout the year, while cases of early and early-disseminated Lyme disease peak in the summer months. Clinicians should integrate seasonal risk in the approach to children with Lyme disease.

Author Contributions: Conceptualization, K.M.S. and L.E.N.; methodology, K.M.S., M.C.M. and L.E.N.; formal analysis, K.M.S., L.E.N. and M.C.M.; data acquisition, M.N.L., F.B., A.D.T., D.N.N., A.C.G. and A.B.K.; writing - original draft preparation, K.M.S. and L.E.N.; funding acquisition, L.E.N. All authors have read and agreed to the published version of the manuscript.

Funding: This research was funded by the Global Lyme Alliance (Stamford, CT, USA). 
Institutional Review Board Statement: The study was conducted according to the guidelines of the Declaration of Helsinki, and approved by the Institutional Review Board (or Ethics Committee) of Boston Children's Hospital (protocol number IRB-P00015747; initial study approval 14 November 2014).

Informed Consent Statement: Informed consent was obtained from all subjects involved in the study.

Data Availability Statement: Not applicable.

Acknowledgments: We would like to acknowledge the patients and families who agreed to study participation as well as the study staff at each of the participating centers who conducted study enrollment. We would also like to acknowledge these additional members of Pedi Lyme Net: Jonathan Bennett (Nemours / Alfred I. duPont Hospital for Children, Wilmington, DE) and John A Branda (Massa-chusetts General Hospital; Boston, MA).

Conflicts of Interest: The authors declare no conflict of interest.

\section{References}

1. Rosenberg, R.; Lindsey, N.P.; Fischer, M.; Gregory, C.J.; Hinckley, A.J.; Mead, P.S.; Paz-Bailey, G.; Waterman, S.H.; Drexler, N.A.; Kersh, G.J.; et al. Vital Signs: Trends in Reported Vectorborne Disease Cases-United States and Territories, 2004-2016. MMWR Morb. Mortal. Wkly. Rep. 2018, 67, 496-501. [CrossRef] [PubMed]

2. Schwartz, A.M.; Hinckley, A.F.; Mead, P.S.; Hook, S.A.; Kugeler, K.J. Surveillance for Lyme Disease-United States, $2008-2015$. MMWR Surveill. Summ. 2017, 66, 1-12. [CrossRef]

3. Shapiro, E.D. Borrelia burgdorferi (Lyme disease). Pediatr. Rev. 2014, 35, 500-509. [CrossRef] [PubMed]

4. Nigrovic, L.E.; Neville, D.N.; Balamuth, F.; Levas, M.N.; Bennett, J.E.; Kharbanda, A.B.; Thompson, A.D.; Branda, J.A.; Garro, A.C.; Pedi Lyme Net Working Group. Pediatric Lyme Disease Biobank, United States, 2015-2020. Emerg. Infect. Dis. 2020, 26, 3099-3101. [CrossRef] [PubMed]

5. Mead, P.; Petersen, J.; Hinckley, A. Updated CDC recommendation for serologic diagnosis of Lyme disease. MMWR Morb. Mortal. Wkly. Rep. 2019, 68, 703. [CrossRef]

6. Bramness, J.G.; Walby, F.A.; Morken, G.; Røislien, J. Analyzing seasonal variations in suicide with Fourier Poisson time-series regression: A registry-based study from Norway, 1969-2007. Am. J. Epidemiol. 2015, 182, 244-254. [CrossRef]

7. Lipsett, S.C.; Monuteaux, M.C.; Fine, A.M. Seasonality of common pediatric infectious diseases. PEC 2021, 37, 82-85. [CrossRef]

8. Nigrovic, L.E.; Thompson, A.D.; Fine, A.M.; Kimia, A. Clinical predictors of Lyme disease among children with a peripheral facial palsy at an emergency department in a Lyme disease-endemic area. Pediatrics 2008, 122, e1080-e1085. [CrossRef]

9. Ogden, N.; Gasmi, S.; Koffi, J.; Barton, M.; Lindsay, L.; Langley, J. Lyme disease in children: Data from the Canadian Paediatric Surveillance Program. Ticks Tick-Borne Dis. 2020, 11, 101347. [CrossRef]

10. Thompson, A.; Mannix, R.; Bachur, R. Acute pediatric monoarticular arthritis: Distinguishing lyme arthritis from other etiologies. Pediatrics 2009, 123, 959-965. [CrossRef]

11. Cohn, K.A.; Thompson, A.D.; Shah, S.S.; Hines, E.M.; Lyons, T.W.; Welsh, E.J.; Nigrovic, L.E. Validation of a clinical prediction rule to distinguish Lyme meningitis from aseptic meningitis. Pediatrics 2012, 129, e46-e53. [CrossRef]

12. Deanehan, J.K.; Kimia, A.A.; Tan Tanny, S.P.; Milewski, M.D.; Talusan, P.G.; Smith, B.G.; Nigrovic, L.E. Distinguishing Lyme from septic knee monoarthritis in Lyme disease-endemic areas. Pediatrics 2013, 131, e695-e701. [CrossRef] [PubMed]

13. Maraspin, V.; Bogovič, P.; Ogrinc, K.; Rojko, T.; Ružić-Sabljić, E.; Kastrin, A.; Strle, K.; Wormser, G.P.; Strle, F. Are Differences in Presentation of Early Lyme Borreliosis in Europe and North America a Consequence of a More Frequent Spirochetemia in American Patients? J. Clin. Med. 2021, 10, 1448. [CrossRef]

14. Guerrero, A.; Escudero, R.; Martí-Belda, P.; Quereda, C. Frecuencia de las manifestaciones clínicas de la borreliosis de Lyme en España [Frequency of the clinical manifestations of Lyme borreliosis in Spain]. Enferm. Infecc. Microbiol. Clin. 1996, 14, 72-79. [PubMed]

15. Wilking, H.; Stark, K. Trends in surveillance data of human Lyme borreliosis from six federal states in eastern Germany, 2009-2012. Ticks Tick Borne Dis. 2014, 5, 219-224. [CrossRef] [PubMed]

16. Chmielewska-Badora, J.; Moniuszko, A.; Żukiewicz-Sobczak, W.; Zwoliński, J.; Piątek, J.; Pancewicz, S. Serological survey in persons occupationally exposed to tick-borne pathogens in cases of co-infections with Borrelia burgdorferi, Anaplasma phagocytophilum, Bartonella spp. and Babesia microti. Ann. Agric. Environ. Med. 2012, 19, 271-274.

17. Pritt, B.S.; Mead, P.S.; Johnson, D.K.H.; Neitzel, D.F.; Respicio-Kingry, L.; Davis, J.P.; Schiffman, E.; Sloan, L.M.; Schriefer, M.E.; Replogle, A.J.; et al. Identification of a novel pathogenic Borrelia species causing Lyme borreliosis with unusually high spirochaetaemia: A descriptive study. Lancet Infect. Dis. 2016, 16, 556-564. [CrossRef]

18. Knox, K.K.; Thomm, A.M.; Harrington, Y.A.; Ketter, E.; Patitucci, J.M.; Carrigan, D.R. Powassan/Deer Tick Virus and Borrelia Burgdorferi Infection in Wisconsin Tick Populations. Vector Borne Zoonotic Dis. 2017, 17, vbz.2016.2082. [CrossRef] [PubMed]

19. Hermance, M.E.; Thangamani, S. Powassan Virus: An Emerging Arbovirus of Public Health Concern in North America. Vector Borne Zoonotic Dis. 2017, 17, 453-462. [CrossRef] 
20. Wormser, G.P.; Dattwyler, R.; Shapiro, E.D.; Halperin, J.; Steere, A.C.; Klempner, M.S.; Krause, P.J.; Bakken, J.S.; Strle, F.; Stanek, G.; et al. The clinical assessment, treatment, and prevention of lyme disease, human granulocytic anaplasmosis, and babesiosis: Clinical practice guidelines by the Infectious Diseases Society of America. Clin. Infect. Dis. 2006, 43, 1089-1134. [CrossRef]

21. Diuk-Wasser, M.A.; Vannier, E.; Krause, P.J. Coinfection by Ixodes Tick-Borne Pathogens: Ecological, Epidemiological, and Clinical Consequences. Trends Parasitol. 2016, 32, 30-42. [CrossRef] [PubMed]

22. Buchan, B.W.; Jobe, D.A.; Mashock, M.; Gerstbrein, D.; Faron, M.L.; Ledeboer, N.A.; Callister, S.M. Evaluation of a Novel Multiplex High-Definition PCR Assay for Detection of Tick-Borne Pathogens in Whole-Blood Specimens. J. Clin. Microbiol. 2019, 57, e00513-19. [CrossRef] [PubMed]

23. Tibbles, C.D.; Edlow, J.A. Does this patient have erythema migrans? JAMA 2007, 297, 2617-2627. [CrossRef] [PubMed]

24. Branda, J.A.; Body, B.A.; Boyle, J.; Branson, B.M.; Dattwyler, R.J.; Fikrig, E.; Gerald, N.J.; Gomes-Solecki, M.; Kintrup, M.; Ledizet, M.; et al. Advances in Serodiagnostic Testing for Lyme Disease Are at Hand. Clin. Infect. Dis. 2018, 66, 1133-1139. [CrossRef] 